\title{
Late Recurrences in Early Breast Cancer: For Whom and How Long Is Endocrine Therapy Beneficial?
}

\author{
Michael Knauer ${ }^{\mathrm{a}}$ Martin Filipits ${ }^{\mathrm{b}} \quad$ Peter Dubskyc $^{\mathrm{c}}$ \\ ${ }^{a}$ Breast Center St. Gallen, Switzerland; bInstitute of Cancer Research, Department of Medicine I; 'Department of Surgery, Comprehensive \\ Cancer Center, Medical University Vienna, Austria
}

\section{Keywords}

Breast neoplasms - Late metastasis - Endocrine therapy . Prediction

\section{Summary}

During the last decade, besides the well-established clinical-pathological predictors for the risk of late recurrence in breast cancer, such as estrogen receptor status, and $\mathrm{T}$ and $\mathrm{N}$ stage, a variety of multigene assays have been shown to improve prognostication and prediction in this setting. Several clinical trials have evaluated the role of extended endocrine therapy with tamoxifen (ATLAS) or aromatase inhibitors (MA.17, NSABP-B33 and ABCSG 6a), and other randomized studies are still ongoing. However, among this patient population, it is still not clear who could benefit from extended therapy and what the optimal treatment duration should be. New multigene assays such as EndoPredict, PAM50 ROR-score, HOXB13/IL17BR ratio and Breast Cancer Index provide significant and relevant prognostic information concerning the likelihood of recurrence beyond 5 years after surgery. The identified low-risk subgroups not only show a very favorable prognosis, they also seem to have only little benefit from extended aromatase inhibitor therapy. Many of these reverse transcriptase/polymerase chain reaction-based techniques have been validated in archived tumor material from large phase III trials, and will soon be available to routine pathology laboratories as an aid in clinical decision-making for patients.

\section{Introduction}

The pattern of recurrence in breast cancer is as heterogeneous as the disease itself. Over the last decade, breast cancer has been shown to comprise a wide spectrum of molecular subtypes, some of which are fragmented further, e.g. the basal-like or triple-negative subtypes [1, 2]. Some subtypes, like the Her2 subtype, preferably metastasize to distinct tissues or organs [3]. The timing of distant recurrence also varies according to the subtype and is non-proportional - while estrogen-receptor (ER)-negative and Her2-positive breast cancers tend to recur within the first 5-7 years with an up to 3-fold higher risk, a lower annual hazard rate for ER-positive tumors exists for the first 5 years after diagnosis [4]. The patterns of late metastases are determined in all age groups by ER status, with the rates of annual recurrences in ER-positive cancers exceeding those of ER-negative tumors after 5-7 years [5]. For many cases, the simple distinction by ER status is a more reliable aid for decision making with regards to extended endocrine therapy than the use of some multigenomic tests such as the 21-gene recurrence score, the prognostic ability of which diminishes when assessing late recurrence risk. This test was initially developed to predict early recurrence, i.e. within the first 5 years; however, the annual risk of metastasis in the low- and intermediate-score group exceeds that of the high-risk score group after 10 years $[4,6]$. Curves of hazard rates over time show a sharp peak for the high-risk group in the first few years after diagnosis, similar to the non-proportional risks for recurrence in ER-negative tumors. These findings suggest different biological mechanisms between early and late recurrences in breast cancer.

\section{Clinical Trials of Extended Adjuvant Endocrine Therapy}

Several phase III clinical trials have been published and others initiated. An overview of extended adjuvant aromatase inhibitor (AI) therapy trials is given in table 1 . The Canadian MA.17 trial randomized 5,187 patients who had completed 5 years of adjuvant tamoxifen to 5 years of either letrozole or placebo [7]. Disease-free survival (DFS) was significantly improved in patients with extended letrozole (hazard ratio (HR) $0.58, \mathrm{p}<0.001$ ). In patients with positive lymph nodes, even overall survival (OS) was improved (HR 0.61, p = 0.04), which constituted an accepted indication for extended endocrine treatment.

The NSABP B-33 trial started recruiting patients in 2001 and had the same setting of extended adjuvant AI therapy

\section{KARGER}

Fax +497614520714

Information@Karger.com

www.karger.com (c) 2014 S. Karger GmbH, Freiburg

$1661-3791 / 14 / 0092-0097 \$ 39.50 / 0$

Accessible online at:

www.karger.com/brc
Michael Knauer, MD, PhD

Breast Center St. Gallen

Rorschacher Strasse 95

9007 St. Gallen, Switzerland

michael.knauer@kssg.ch 
Table 1. Overview of clinical trials on extended adjuvant aromatase inhibitor therapy. The first 3 trials have been published

\begin{tabular}{lll}
\hline Trial & Patients, $\mathrm{n}$ & Study question \\
\hline NCIC MA.17 [7] & 5,187 & letrozole vs. placebo \\
NSABP B33 [8] & 1,598 & exemestane vs. placebo \\
ABCSG 6a [9] & 856 & anastrozole vs. no treatment \\
MA.17R & 1,800 & late letrozole \\
LEAD & 4,050 & letrozole duration \\
NSABP B42 & 3,966 & letrozole vs. placebo \\
ABCSG 16 SALSA & 3,486 & anastrozole duration \\
DATA & 1,900 & anastrozole duration \\
SOLE & 4,800 & intermittent letrozole \\
\hline
\end{tabular}

with exemestane [8]. In 2003, when the positive results of the MA.17 study had become available, the trial was unblinded after randomization of 1,598 patients. Even though a substantial proportion of patients chose to crossover from placebo to exemestane $(44 \%)$, after 4 years of follow-up, a borderlinesignificant improvement in DFS (HR 0.68, p = 0.07) was observed. However, the absolute difference was only $2 \%$ in this population (91 vs. $89 \%$ DFS at 4 years).

In the Austrian ABCSG 6a study, 856 patients were randomized to 3 years of anastrozole or placebo after having completed 5 years of tamoxifen treatment with or without the addition of the AI aminoglutethimide within the preceding ABCSG 6 trial [9]. After a median follow-up of 62 months, the investigators found a significant improvement in recurrence-free survival (RFS) by extending endocrine therapy to 8 years (HR 0.62, $\mathrm{p}=0.031$ ).

Despite the significant and clinically relevant relative risk (RR) reduction of $32-43 \%$ for recurrence, the results of these well-conducted trials cannot be transferred into clinical routine for many patients, since at present most postmenopausal patients are being treated with an AI for at least 2-3 years in the adjuvant setting.

The worldwide ATLAS trial randomized nearly 13,000 patients who had completed 5 years of tamoxifen to either stopping tamoxifen or continuing for another 5 years as extended therapy [10]. In the years 5-9, there was a small RR reduction of $10 \%$, or $1.4 \%$ in absolute numbers. After stopping treatment at 10 years, the Kaplan-Meier curves started to separate, resulting in $25 \%$ relative and $3.7 \%$ absolute risk reduction at 15 years of follow-up. Regarding breast cancer-related death, extended tamoxifen therapy resulted in a $29 \%$ relative and $2.8 \%$ absolute reduction of risk after 15 years. With regards to side effects, the most commonly observed toxicities were an increased risk of endometrial cancer (RR 1.74) and pulmonary embolism (RR 1.87). On the other hand, a significant decrease in ischemic heart disease was noted (RR 0.76) and no increase in stroke incidence was found, which led to the conclusion that the benefits of this treatment seemed to outweigh the risks substantially. The risks and benefits of 10 years of tamoxifen, therefore, have to be discussed individually with each patient, taking into account previous side effects and personal preferences. For some patients who are still premenopausal 5 years after diagnosis, continuing with tamoxifen is a valid option. Considering the overall numbers, to avoid 6 breast cancer-related deaths, the number of patients that needed to be treated would be around 340 , and that at the cost of 3 additional endometrial cancers and 1 pulmonary embolism. However, the absolute increase of endometrial cancer was only $0.2 \%$ in the ATLAS trial.

What we have learned from the clinical trials of extended endocrine therapy with regard to classical clinical-pathological features is that a positive lymph node status and larger tumor size constitute risk factors for late recurrences [11]. The same factors as well as premenopausal status and co-expression of ER and progesterone receptor (PR) were found to be indicative for extended AI benefit in these trials [7, 9, 12].

\section{Multigenomic Tests for Prediction of Late Recurrence}

Several multigene assays have been developed to predict recurrence risk for individual breast cancer patients. Among others, the 21-gene recurrence score (Oncotype Dx) and the 70 -gene profile (MammaPrint) have been used in several clinical trials, including the TailorX and Mindact phase III trials $[13,14]$. These studies have finished recruiting patients, and the results are eagerly awaited. Originally, these tests were developed and trained on tumor samples obtained from patients who had a recurrence within the first years. As mentioned above, although these tests are clinically useful for predicting adjuvant chemotherapy benefit, they were not developed to predict late recurrences and benefit from extended endocrine treatment. When focusing on multigenomic tests that provide additional prognostic information beyond ER status concerning the likelihood of recurrence after 5 years, EndoPredict (EP), the intrinsic subtype test PAM50 (Prosigna), and HOXB13/IL17BR (included in the Breast Cancer Index (BCI)) have to be discussed, although none of these have specifically been developed as a predictive marker for extended endocrine treatment and prognostication of late recurrences.

The EP signature, which is a reverse transcriptase-polymerase chain reaction (RT-PCR)-based assay that includes 8 genes of interest and 3 normalization genes, was originally developed in a set of 964 patient samples treated with tamoxifen monotherapy. The 2 independent validation cohorts consisted of tumor samples from the prospective ABCSG 6 and 8 trials $[15,16]$. The EP low-risk group consisted of $49 \%$ of patients and had a significantly better outcome regarding occurrence of distant metastasis before and after 5 years of follow-up (HR 2.80, p < 0.001 and HR 3.28, p = 0.002, respectively). In a multivariate analysis with inclusion of age, nodal status, tumor size, Ki-67, grade and treatment, only N stage and the EP signature were independent prognostic parameters [17]. When including the clinical-pathological features nodal status and tumor size into the so-called EPclin, this
98

Breast Care 2014;9:97-100
Knauer/Filipits/Dubsky 
combination showed the best performance in predicting laterelapse events [18]. The authors used several (combinations of) different pathological tumor features and the computerbased algorithm AdjuvantOnline! together with EP [18]; in every setting the multigene score improved the prognostic performance of the clinical parameters. When using EPclin, the low-risk group comprised $64 \%$ of patients with a distant RFS (DRFS) of $98.2 \%$, in contrast to $87.7 \%$ in the high-risk group after 10 years (HR 6.25, p < 0.001).

The PAM50 Risk of Recurrence (ROR) score was developed in 2009, after the 'intrinsic subtypes' have been described nearly 10 years earlier [1, 19]. The RT-PCR-based assay was validated in 786 specimens uniformly treated with adjuvant tamoxifen and comprises 50 genes that define these subtypes. In contrast to some other multigene tests with testing in a central company laboratory, the ROR score can be generated locally in qualified routine pathology laboratories. Gnant et al. [20] recently reported 10-year results of the ROR score from 1,478 patients who were treated in the ABCSG 8 study. 1,620 formalin-fixed paraffin-embedded tumor blocks were collected after obtaining further consent from 1,671 patients. Of these, $91.2 \%$ passed the PAM50 quality control and could be classified into 3 distinct risk groups. The probabilities of staying free of distant metastasis were 96.7, 91.3 and $79.9 \%$ for the low-, intermediate- and high-risk subgroups, respectively, in which patients were nearly equally distributed. In addition to the generation of the ROR score, PAM50 also assigns the respective intrinsic subtype to all cases: $\sim 66 \%$ of tumors were assigned to the Luminal A and $\sim 33 \%$ to the Luminal B subgroup within this population of hormone receptor-positive patients. A small proportion of patients were re-classified into a different intrinsic subtype by PAM50 (3.3\% Her2-positive and 0.5\% basal-like subgroups). Compared to Luminal A tumors, Luminal B tumors had a significantly worse prognosis at 10 years (HR 2.85, $\mathrm{p}<0.001$ ), with, for example, $90.6 \%$ DRFS in the Luminal A node-positive subgroup, indicating that positive lymph nodes are more an indication of tumor burden than aggressive biology in these patients. Moreover, it has been shown that the PAM50 ROR score and ROR-based risk groups can differentiate breast cancer patients with respect to their risk for late distant recurrence beyond that achievable with established clinical-pathological risk factors [21]. Between years 5 and 15, an absolute risk of distant recurrence of $2.4 \%$ in the low ROR-based risk group, as compared to $17.5 \%$ in the high ROR-based risk group, was observed. The PAM50 ROR score was also evaluated in 1,017 tumor samples from the TransATAC study [22, 23]. The ROR score significantly added prognostic information beyond clinical risk assessment in both node negative and positive, as well as Her2-negative, patients with the best $\mathrm{C}$-index of 0.78 by combining ROR score with a clinical treatment score (CTS) vs. 0.73 for CTS. This index also exceeded the prognostic value of the 21-gene recurrence score in this trial (C-index 0.76). As a second comparison, the immunohisto- chemical IHC4 score was added with equal prognostic information as the ROR score for all patients. However, in the Her2-negative/node-negative group, the ROR score performed better. The authors found a continuous relationship between 10-year distant recurrence risk and ROR score with fewer patients being categorized as intermediate and more as high risk than with the 21-gene score.

The RT-PCR-based HOXB13/IL17BR (H/I) 2-gene ratio was also developed for prediction of recurrence risk in ERpositive, node-negative early breast cancer [24]. Sgroi et al. [25] recently published a case-control study of 83 recurrent patients and 166 non-recurrent patients from the MA.17 study of extended letrozole therapy. Regarding prognostication of late relapses, the $\mathrm{H} / \mathrm{I}$ ratio was significantly associated with outcome in the univariate analysis, and it was of borderline significance in the multivariate analysis, including clinical factors such as age, tumor size, grade, nodal status, ER, PR and Her2 (odds ratio $(O R) 2.15, p=0.05$ ). When the same analysis was done for predicting treatment benefit of extended letrozole, a high $\mathrm{H} / \mathrm{I}$ ratio was associated with a $67 \% \mathrm{RR}$ reduction in the placebo arm (OR $0.33, \mathrm{p}=0.006$ ). The absolute reduction in relapse risk at 5 years was $16.5 \%$, with the test for interaction being significant and an 89.5 vs. $73 \%$ RFS rate for the letrozole vs. placebo group, respectively.

The BCI assay integrates the $\mathrm{H} / \mathrm{I}$ ratio and the 5-gene Molecular Grade Index (MGI), which recapitulates grade and proliferation, and has shown to be of prognostic value in ERpositive breast cancer [26]. Sgroi and colleagues [27, 28] used archived tumor material from the TransATAC study to compare the prognostic ability of the BCI, the 21-gene recurrence score and the immunohistochemical IHC4 score. The IHC4 score measures protein expression of the 4 most widely used biomarkers ER, PR, Her2 and Ki-67 [29]. The results of BCI are given in a similar fashion to the 21-gene recurrence score and the PAM50 ROR score, i.e. low, intermediate and high recurrence risk. The authors identified a relevant subgroup of $61 \%$ of patients with BCI low risk, and this subgroup experienced a very low risk for recurrences of $3.5 \%$ in the years 5-10 of follow-up. Both the IHC4 and the 21-gene score failed to predict for late distant recurrences in this study, although they were highly predictive for early relapse.

\section{Conclusions}

In conclusion, besides the well-established clinical-pathological predictors for late recurrence risk in breast cancer such as ER status, and $\mathrm{T}$ and $\mathrm{N}$ stage, a variety of multigene assays have been shown to improve prognostication and prediction in this setting. EP, PAM50 ROR score, $\mathrm{H} / \mathrm{I}$ ratio and BCI provide significant and relevant prognostic information concerning the likelihood of recurrence beyond 5 years after surgery. The identified low-risk subgroups not only showed a very 
favorable prognosis, they also seem to have only very little benefit from extended aromatase inhibitor therapy. Many of these RT-PCR-based techniques have been validated in archived tumor material of large phase III trials and will soon be available for routine pathology laboratories to assist in clinical decision making for patients.

\section{Disclosure Statement}

M.K. received research support from Agendia. M.F. reported consultancy for AstraZeneca, NanoString Technologies, Sividon and payment for lectures of AstraZeneca, Boehringer Ingelheim, Eli Lilly, Merck, Pfizer, Roche, and Sividon. P.D. received travel grants and lecture fees from Sividon, research support from Agendia and honoraria for advisory board membership from Genomic Health.

\section{References}

1 Perou CM, Sørlie T, Eisen MB, et al.: Molecular portraits of human breast tumours. Nature 2000;406:747-752.

2 Lehmann BD, Bauer JA, Chen X, et al.: Identification of human triple-negative breast cancer subtypes and preclinical models for selection of targeted therapies. J Clin Invest 2011;121:27502767.

-3 Sihto H, Lundin J, Lundin M, et al.: Breast cancer biological subtypes and protein expression predict for the preferential distant metastasis sites: A nationwide cohort study. Breast Cancer Res 2011;13:R87.

4 Jatoi I, Anderson WF, Jeong J-H, Redmond CK: Breast cancer adjuvant therapy: Time to consider its time-dependent effects. J Clin Oncol 2011;29: 2301-2304.

5 Yu K-D, Wu J, Shen Z-Z, Shao Z-M: Hazard of breast cancer-specific mortality among women with estrogen receptor-positive breast cancer after five years from diagnosis: implication for extended endocrine therapy. J Clin Endocrinol Metab 2012;97:E2201-2209.

6 Fan C, Oh DS, Wessels L, et al.: Concordance among gene-expression-based predictors for breast cancer. N Engl J Med 2006;355:560-569.

7 Goss PE, Ingle JN, Martino S, et al.: Randomized trial of letrozole following tamoxifen as extended adjuvant therapy in receptor-positive breast cancer: Updated findings from NCIC CTG MA.17. J Natl Cancer Inst 2005;97:1262-1271.

$\checkmark$ Mamounas EP, Jeong J-H, Wickerham DL, et al.: Benefit from exemestane as extended adjuvant therapy after 5 years of adjuvant tamoxifen: Intention-to-treat analysis of the National Surgical Adjuvant Breast And Bowel Project B-33 trial. J Clin Oncol 2008;26:1965-1971.

-9 Jakesz R, Greil R, Gnant M, et al.: Extended adjuvant therapy with anastrozole among postmenopausal breast cancer patients: Results from the randomized Austrian Breast and Colorectal Cancer Study Group Trial 6a. J Natl Cancer Inst 2007 99:1845-1853.

10 Davies C, Pan H, Godwin J, et al.: Long-term effects of continuing adjuvant tamoxifen to 10 years versus stopping at 5 years after diagnosis of oestrogen receptor-positive breast cancer: ATLAS, a randomised trial. Lancet 2013;381:805-816.
11 Kennecke HF, Olivotto IA, Speers C, et al.: Late risk of relapse and mortality among postmenopausal women with estrogen responsive early breast cancer after 5 years of tamoxifen. Ann Oncol 2007; 18:45-51.

12 Goss PE, Ingle JN, Martino S, et al.: Impact of premenopausal status at breast cancer diagnosis in women entered on the placebo-controlled NCIC CTG MA17 trial of extended adjuvant letrozole. Ann Oncol 2013;24:355-361.

13 Zujewski JA, Kamin L: Trial assessing individualized options for treatment for breast cancer: The TAILORx trial. Future Oncol 2008;4:603-610.

14 Cardoso F, Van't Veer L, Rutgers E, et al.: Clinical application of the 70-gene profile: the MINDACT trial. J Clin Oncol 2008;26:729-735.

15 Filipits M, Rudas M, Jakesz R, et al.: A new molecular predictor of distant recurrence in ERpositive, HER2-negative breast cancer adds independent information to conventional clinical risk factors. Clin Cancer Res 2011;17:6012-6020.

16 Dubsky P, Filipits M, Jakesz R, et al.: EndoPredict improves the prognostic classification derived from common clinical guidelines in ER-positive, HER2negative early breast cancer. Ann Oncol 2013; 24:640-647.

17 Dubsky P, Brase JC, Jakesz R, et al.: The EndoPredict score provides prognostic information on late distant metastases in $\mathrm{ER}^{+} / \mathrm{HER} 2$ breast cancer patients. Br J Cancer 2013;109:2959-2964.

18 Ravdin PM, Siminoff LA, Davis GJ, et al.: Computer program to assist in making decisions about adjuvant therapy for women with early breast cancer. J Clin Oncol 2001;19:980-991.

19 Nielsen TO, Parker JS, Leung S, et al.: A comparison of PAM50 intrinsic subtyping with immunohistochemistry and clinical prognostic factors in tamoxifen-treated estrogen receptor-positive breast cancer. Clin Cancer Res 2010;16:5222-5232.

20 Gnant M, Filipits M, Greil R, et al.: Predicting distant recurrence in receptor-positive breast cancer patients with limited clinicopathological risk: Using the PAM50 Risk of Recurrence score in 1478 postmenopausal patients of the ABCSG- 8 trial treated with adjuvant endocrine therapy alone. Ann Oncol 2014;25:339-345.
21 Filipits M, Nielsen TO, Rudas M, et al.: The PAM50 Risk-of-Recurrence Score Predicts Risk for Late Distant Recurrence after Endocrine Therapy in Postmenopausal Women with EndocrineResponsive Early Breast Cancer. Clin Cancer Res. 2014;20:1298-1305.

22 Dowsett M, Allred C, Knox J, et al.: Relationship between quantitative estrogen and progesterone receptor expression and human epidermal growth factor receptor 2 (HER-2) status with recurrence in the Arimidex, Tamoxifen, Alone or in Combination trial. J Clin Oncol 2008;26:1059-1065.

23 Dowsett M, Sestak I, Lopez-Knowles E, et al.: Comparison of PAM50 risk of recurrence score with oncotype DX and IHC4 for predicting risk of distant recurrence after endocrine therapy. J Clin Oncol 2013;31:2783-2790.

24 Goetz MP, Suman VJ, Ingle JN, et al.: A two-gene expression ratio of homeobox 13 and interleukin17B receptor for prediction of recurrence and survival in women receiving adjuvant tamoxifen. Clin Cancer Res 2006;12:2080-2087.

25 Sgroi DC, Carney E, Zarrella E, et al.: Prediction of late disease recurrence and extended adjuvant letrozole benefit by the HOXB13/IL17BR biomarker. J Natl Cancer Inst 2013;105:1036-1042.

26 Ma X-J, Salunga R, Dahiya S, et al.: A five-gene molecular grade index and HOXB13:IL17BR are complementary prognostic factors in early stage breast cancer. Clin Cancer Res 2008;14:2601-2608.

27 Sgroi DC, Sestak I, Cuzick J, et al.: Prediction of late distant recurrence in patients with oestrogen-receptor-positive breast cancer: a prospective comparison of the breast-cancer index (BCI) assay, 21-gene recurrence score, and IHC4 in the TransATAC study population. Lancet Oncol 2013;14:1067-1076.

28 Cuzick J, Sestak I, Baum M, et al.: Effect of anastrozole and tamoxifen as adjuvant treatment for early-stage breast cancer: 10-year analysis of the ATAC trial. Lancet Oncol 2010;11:1135-1141.

29 Cuzick J, Dowsett M, Pineda S, et al.: Prognostic value of a combined estrogen receptor, progesterone receptor, $\mathrm{Ki}-67$, and human epidermal growth factor receptor 2 immunohistochemical score and comparison with the Genomic Health recurrence score in early breast cancer. J Clin Oncol 2011;29: 4273-4278. 